\title{
PERANCANGAN APLIKASI AUGMENTED REALITY PEMBELAJARAN TATA SURYA DENGAN MENGGUNAKAN MARKER BASED TRACKING
}

\author{
SUSANNA DWI YULIANTI KUSUMA \\ Staf Pengajar Fakultas Teknik Prodi Teknik Informatika \\ Universitas Pamulang, Tangerang Selatan, Banten \\ e-mail:dosen00682@unpam.ac.id
}

\begin{abstract}
ABSTRAK
Teknologi saat ini telah menjadi bagian dari kehidupan manusia, banyak teknologi diciptakan untuk menjadi kehidupan manusia. Salah satunya, teknologi peralatan telekomunikasi atau yang biasa kita sebut smartphone. Smartphone tidak hanya sebagai alat telekomunikasi saja tetapi banyak fitur yang sangat membantu dalam kehidupan sehari-hari, seperti media pembelajaran, baik itu media pembelajaran berupa tulisan maupun gambar. Tata surya adalah ilmu dasar yang bisa kita dapatkan di sekolah. Tidak adanya laboratorium IPA dapat diuji di sekolah-sekolah yang digunakan sebagai ruang praktis dan mendukung tata surya, sehingga siswa akan kehilangan kesempatan untuk mengembangkan keterampilan, melakukan pengamatan dan mengurangi rasa ingin tahu siswa. Dengan demikian buku menjadi satu-satunya media untuk mempelajari tata surya. Augmented reality adalah teknologi yang mengubah dunia nyata dan dunia dua dimensi yang diproyeksikan dalam ruang nyata. Augmented reality telah berkembang sebagai media pembelajaran di banyak bidang ilmiah. Dengan memanfaatkan buku sebagai satu-satunya media maka penulis menggunakan buku teks sebagai marker untuk Augmented reality dengan metode marker tracking yang dapat digunakan di android.
\end{abstract}

Kata kunci: Augmented Reality, Tata Surya, Pembelajaran

\section{PENDAHULUAN}

Teknologi yang telah banyak berkembang juga berkembang penggunaannya, seperti digunakan dalam sebuah media edukasi, dengan perkembangan teknologi saat ini, terutama di teknologi Augmented Reality dapat di terapkan sebagai sebuah media edukasi pengenalan tata surya agar dapat membantu pengguna mendapatkan informasi mengenai tata surya dengan cara yang lebih menarik yaitu dengan menggunakan teknologi. Minat membaca buku pada anak indonesia sangat rendah hanya $0,01 \%$ atau sekitar 10,000 jiwa [6], dengan bantuan teknologi diharapkan dapat meningkatkan jumlah pembaca buku, khususnya anak-anak.

Teknologi mobile device sudah menjadi bagian dari kehidupan masyarakat modern, baik muda maupun tua tidak bisa lepas dari smartphone mereka. Android merupakan jenis Sistem Operasi yang paling popular di smartphone, pada tahun 2015 pengguna Android di indonesia sebanyak 41 juta pengguna[8]. Sebuah smartphone pada saat ini tidak hanya berfungsi untuk menelpon atau mengirim pesan saja, sudah banyak fitur canggih dari berbagai macam aplikasi. Salah satunya yaitu aplikasi android sebagai media edukasi melalui sebuah smartphone.

Augmented Reality (AR) adalah penggabungan antara objek virtual dengan objek nyata[2]. Augmented Reality dapat dipublikasikan untuk semua indra, termasuk pendengaran, sentuhan dan penciuman. Selain digunakan dalam bidang-bidang seperti kesehatan, militer, industri manufaktur, augmented reality juga telah diaplikasikan dalam perangkat-perangkat yang digunakan orang banyak, seperti pada smartphonedengan memanfaatkan fitur kamera yang ada di hampir semua smartphone saat ini. Tujuan utama dari Augmented Reality adalah untuk menciptakan lingkungan baru dengan menggabungkan interaktivitas lingkungan nyata dan virtual secara real time sehingga pengguna merasa bahwa lingkungan yang diciptakan adalah nyata[2].

Marker based tracking merupakan sebuah metode dalam Augmented Reality, fungsi sebuah marker yaitu sebagai media yang berperan dalam menampilkan objek virtual diatasnya, marker akan dikenali oleh sebuah aplikasi yang telah 
ditanamkan teknologi augmented reality melalui perangkat kamera dengan mengenali posisi dan orientasi dari marker tersebut yaitu berupa 3 sumbu $x, y$ dan $z[10]$.

Sistem tata surya sebagai salah satu bidang pembelajaran ilmu pengetahuan alam dan menjadikan bidang ilmu yang menarik untuk dipelajari. Sistem tata surya sendiri merupakan ilmu dasar dalam bidang pelajaran ilmu pengetahuan alam yang di dapat di tingkat pendidikan Sekolah Dasar kelas V (lima) dan kelas VI (Enam), dimana hal yang dibahas pada umumnya yaitu mengenai matahari, planet dan objek-objek lain yang mengelilingi matahari.

Sistem yang ada pada saat ini, umumnya anak-anak mengenal tata surya hanya dari media buku yang didapatkan dari sekolah. Buku yang digunakan dalam kagiatan belajar tata surya tentu saja menampilkan gambar objek dari anggota tata surya, namun untuk mengenal tata surya akan lebih baik menggunakan sebuah alat peraga seperti planet-planet, matahari dan objek lainnya sebagai sebuah alat pendukung agar dapat lebih baik untuk menyerap pelajaran tata surya. Namun tidak adanya Laboratorium IPA di MI AL HUDA Ciputat sebagai ruangan praktikum dan penunjang pembelajaran, maka siswa kehilangan suatu kesempatan untuk mengembangkan keterampilan, melakukan pengamatan dan dapat mengurangi rasa keingintahuan siswa. Dengan begitu harus ada suatu sistem yang dapat menggantikan peran laboratorium IPA yang tidak ada di sekolah dalam mempelajari Tata Surya.

\section{METODE PENELITIAN}

Tata surya adalah suatu kelompok benda langit, yaitu matahari dan planet-planetnya yang terdiri dari Merkurius, Venus, Bumi, Mars, Jupiter, Saturnus, Uranus dan Neptunus beserta 165 buah satelit planet yang sudah diketahui sampai sekarang, serta objek-objek tata surya lainnya, seperti asteroid, planet katai, meteoroid, planetoid komet, dan debu antarplanet, yang bergerak mengikuti hukum-hukum dinamika newton[1].

Pembelajaran tata surya yang akan dibuat menerapkan Augmented Reality (AR) dengan menggunakan marker based tracking. Augmented Reality (AR) itu sendiri adalah penggabungan antara objek virtual dengan objek nyata. Sebagai contoh adalah saat pembawa acara televisi membawakan berita, ada animasi atau objek virtual yang ikut bersamanya, jadi di berada seolah-olah di dalam dunia virtual tersebut, padahal itu adalah teknik penggabungan antar dunia virtual dengan dunia nyata yang dinamakan dengan Augmented Reality[2]. Selain menambahkan benda maya dalam lingkungan nyata, Augmented Reality juga berpotensi menghilangkan benda yang sudah ada. Menambahkan sebuah lapisan gambar maya dimungkinkan untuk menghilangkan atau menyembunyikan lingkungan nyata dari pandangan pengguna.

Tujuan utama dari Augmented Reality adalah menyederhanakan kehidupan pengunanya dengan cara membawa informasi virtual, bukan hanya menambahkan lapisan atau layer saja, tetapi juga memperlihatkan pengelihatan tidak langsung dari lingkungan dunia nyata, sehingga dapat dikatakan bahwa Augmented Reality meningkatkan pandangan dan interaksi pengguna dengan dunia nyata[3].

Augmented Reality ini dibuat dengan menggunakan Marker Based Tracking. Marker Based Tracking merupakan ilustrasi hitam dan putih dengan batas hitam tebal dan latar belakang putih. Komputer akan mengenali posisi dan orientasi marker dan menciptakan dunia virtual $3 \mathrm{D}$ yaitu titik $(0,0,0)$ dan 3 sumbu $\mathrm{X}, \mathrm{Y}$, dan $\mathrm{Z}$. Marker Based Tracking ini sudah lama dikembangkan sejak tahun 80 -an dan pada awal 90-an mulai dikembangkan untuk penggunaan Augmented Reality[5].

Pada penelitian ini yang digunakan adalah Markerless Augmented Reality, namun untuk marker yang digunakan bukan sembarang marker tetapi marker yang telah diregistrasikan pada Vuforia, agar dapat dikenal oleh AR devices. Jenis marker pada vuforia yaitu bersifat markerless, artinya bentuk marker yang akan digunakan dapat berupa gambar bebas namun harus sudah diregistrasikan di situs resmi vuforia. Berikut ini akan dijelaskan cara untuk mendaftarkan markernya:

Terlebih dahulu kita harus membuat lisensinya, dengan cara sebagai berikut :

1. Login ke situs vuforia menggunakan akun yg telah terdaftar.

2. Pilih Menu Develop.

3. Pilih License Manager. Kemudian Add License Key.

4. Isikan Aplication Name lalu Next, kemudian centang sarat dan ketentuan dari Vuforia lalu Confirm.

Setelah pembuatan lisensi selesai, maka selanjutnya akan dijelaskan proses pembuatan database marker, sebagai berikut :

1. Masih pada menu Develop pilih Target Manager, kemudian Add Database. 
2. Isi Database Name lalu pilih Device pada Type, kemudian pilih License Key yang telah dibuat sebelumnya.

3. Setelah database berhasil dibuat, tambahkan target marker dengan cara pilih terlebih dahulu database yang dibuat tadi.

4. Add Target dan Import file yang akan dijadikan marker. Isi nama serta ukuran filenya.

5. Selesai.

Untuk mengunduh objek yang sudah kita daftarkan sebagai marker dapat dilakukan dengan cara berikut:

1. Centang objek yang akan digunakan sebagai marker.

2. Klik download selected target.

3. Pada form download selected target pilih sesuai yang dibutuhkan.

4. Klik Download.

5. Tunggu beberapa saat hingga proses pengunduhan database untuk objek yang dipilih selesai.

Untuk membuat aplikasi ini juga dibutuhkan vuforia SDK. Vuforia adalah Augmented Reality Software Development Kit (SDK) untuk perangkat mobile yang memungkinkan membuat aplikasi Augmented Reality. Dulunya lebih dikenal sebagai QCAR (Qualcomm Company Augmented Reality). Ini menggunakan teknologi Computer Vision untuk mengenali dan melacak gambar planar (Target Image) dan objek 3D sederhana seperti, seperti kotak secara realtime[7].

Menurut [4] Vuforia SDK memerlukan beberapa komponen penting agar dapat bekerja dengan baik. Komponen-komponen tersebut antara lain:

a. Kamera

Kamera dibutuhkan untuk memastikan bahwa setiap frame ditangkap dan diteruskan secara efisien ke tracker. Para developer hanya tinggal memberi tahu kamera kapan meraka mulai menangkap dan berhenti.

b. Image Controller

Mengkonversi dari format kamera (misalnya YUV12) ke dalam format yang dapat dideteksi oleh OpenGL (misalnya RGB565) dan untuk pelacakan secara internal (misalnya luminance).

c. Ttracker

Mengandung algoritma computer vision yang dapat mendeteksi dan melacak objek dunia nyata yang ada pada video kamera. Berdasarkan gambar dari kamera, algoritma yang berbeda bertugas untuk mendeteksi trackable baru, dan mengevaluasi virtual button. Hasilnya akan disimpan dalam state Object yang akan digunakan oleh video background renderer dan dapat diakses dari application code.

d. Video Background Renderer

Me-render gambar dari kamera yang tersimpan didalam state object. Performa dari video background renderer sangat berkantung pada device yang digunakan.

e. Application Code

Menginisialisasi semua komponen di atas dan melakukan tiga tahapan penting dalam application code seperti :

1. Query State Object pada target baru yang terdeteksi atau marker.

2. Update logika aplikasi setiap input baru dimasukan.

3. Rendergrafis yang ditambahkan (augmented).

\section{f. Target Resources}

Dibuat menggunakan on-line target management system assets yang diunduh berisi sebuah konfigurasi xml - config.xml yang memungkinkan developer untuk mengkonfigurasi beberapa fitur dalam trackable dan binary file yang berisi database trackable.

\section{PEMBAHASAN}

Tahap implementasi merupakan tahap penterjemahan perancangan berdasarkan hasil analisis ke dalam suatu bahasa pemrograman tertentu serta penerapan perangkat lunak yang dibangun pada lingkungan yang sesungguhnya. Dalam aplikasi Tata Surya AR ini implementasi dilakukan di Madrasah YAYASAN SURYA SAKTI MI AL HUDA CIPUTAT dimana nanti murid-murid kelas 5 dan 6 sebagai user akan mencoba aplikasi ini.

\subsection{Sistem Interface}

Antarmuka (interface) adalah salah satu layanan yang disediakan sistem operasi sebagai sarana interaksi antar pengguna dengan sistem operasi dan juga merupakan komponen sistem operasi yang bersentuhan langsung dengan pengguna, terdapat dua jenis antarmuka, yaitu Command Line Inteface (CLI) dan Graphical User Interface[9]. Pada aplikasi Augmented Reality pembelajaran Tata surya dengan Vuforia ini terdapat beberapa tampilan dari aplikasi ini, 
seperti tampilan menu, tampilan kamera, tampilan info, dan lainnya.

\subsection{Tampilan Aplikasi}

Tampilan ini merupakan tampilan menumenu pada aplikasi Tata Surya AR, diantara yaitu:

a. Tampilan Menu Utama

Pada tampilan ini terdapat 4 buah tombol yang dapat dipilih oleh pengguna, yaitu tombol Start AR, tombol tahukah kamu, tombol bantuan dan tombol Keluar. Berikut adalah tampilan Menu Utama:

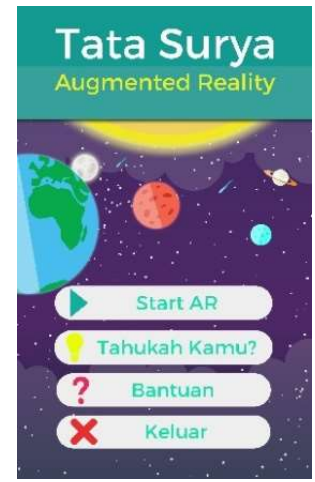

Gambar 2. Menu Utama

\begin{abstract}
Pada Menu Tahukah Kamu menampilkan beragam informasi yang berkaitan dengan tata surya, seperti faktafakta menarik tentang tata surya.Tujuan dari menu ini adalah untuk menambah pengetahuan mengenai objek tata surya selain planet-planet, karena masih banyak hal yang menarik lainnya di tata surya untuk dipelajari.
\end{abstract}



Gambar 3.Tampilan Menu Tahukah kamu informasi

Pada Menu Bantuan menampilkan informasi untuk pengguna aplikasi tentang bagaimana cara menggunakan aplikasi ini, ada tiga step atau langkah cara penggunaannya. Pengguna hanya perlu mengusap layar smartphone secara horizontal untuk melihat cara penggunaan selanjutnya.



\section{Gambar 4. Tampilan menu Bantuan}

b. Tampilan Objek 3 Dimensi Planet Bumi

Tampilan objek 3 Dimensi planet bumi akan muncul saat user mengarahkan kamera ke marker yang menjelaskan tentang planet bumi sehingga aplikasi akan menampilkan objek 3D bumi lewat kamera.

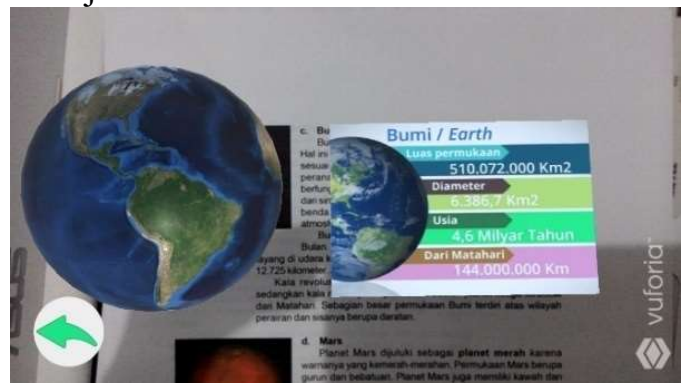

Gambar 5. Tampilan 3D Bumi

c. Tampilan Objek 3D Bulan

Tampilan objek 3 Dimensi bulan akan muncul saat user mengarahkan kamera ke marker yang menjelaskan tentang bulan sehingga aplikasi akan menampilkan objek $3 \mathrm{D}$ bulan lewat kamera.

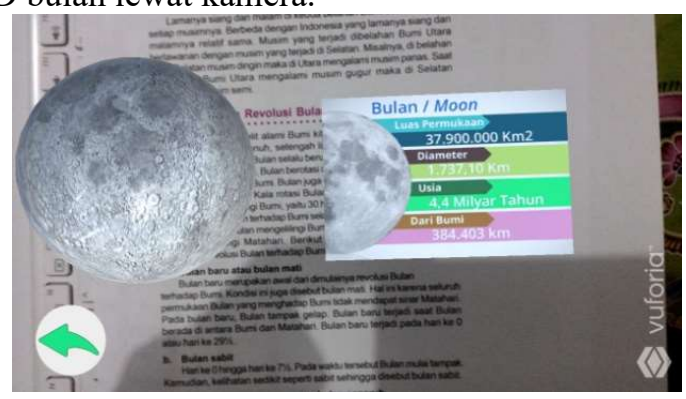

Gambar 6. Objek 3D Bulan

d. Tampilan objek 3D Matahari 
Tampilan objek 3D Matahari akan muncul saat user mengarahkan kamera ke marker yang menjelaskan tentang Matahari sehingga aplikasi akan menampilkan objek 3D Matahari beserta informasi planet tersebut melalui kamera.

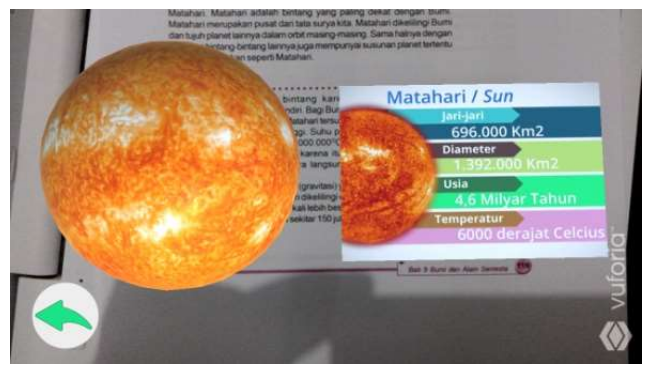

Gambar 7. Objek 3D Matahari

e. Tampilan objek 3D Asteroid

Tampilan objek 3D Asteroid akan muncul saat user mengarahkan kamera ke marker yang menjelaskan tentang asteroid sehingga aplikasi akan menampilkan objek 3D asteroid beserta informasinya melalui kamera.

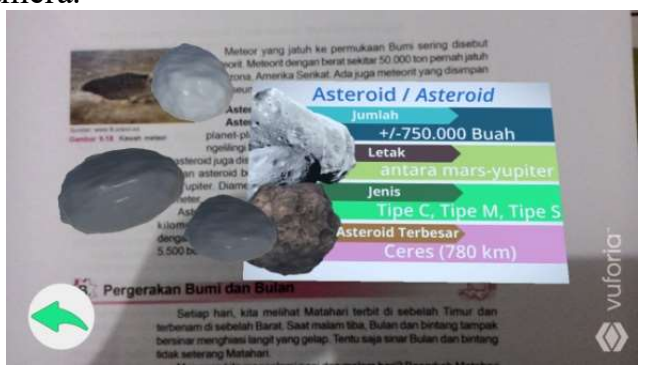

Gambar 8. Objek 3D Asteroid

\subsection{Tampilan Marker}

Marker ini merupakan tampilan dari marker yang dijadikan untuk aplikasi ini, diantaranya:

a. Marker Planet Bumi

Marker planet bumi, jika pengguna mengarahkan kamera pada buku dengan menggunakan aplikasi Tata Surya AR ini maka kamera pada aplikasi akan menampilkan objek 3 Dimensi planet bumi dan informasi mengenai planet bumi.

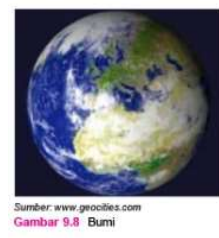

Gambar 9. Marker Planet Bumi b. Marker Bulan
Marker ini merupakan marker Bulan, jika kamera pada aplikasi Tata Surya AR ini maka aplikasi akan menampilkan objek 3D Bulan dan informasi mengenai Bulan.

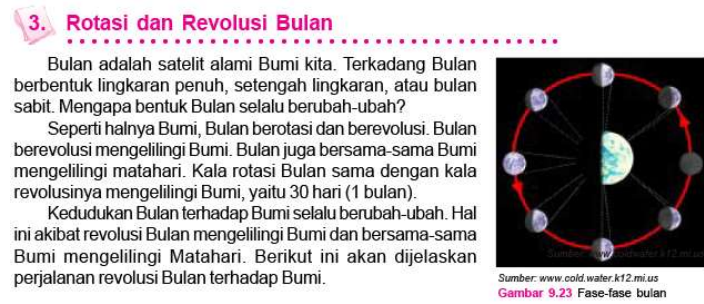

\section{Gambar 10. Marker Bulan}

c. Marker Matahari

Marker ini merupakan marker matahari, jika kamera pada aplikasi Tata Surya AR diarahkan ke marker ini maka aplikasi akan menampilkan objek 3D matahari dan informasi mengenai matahari.

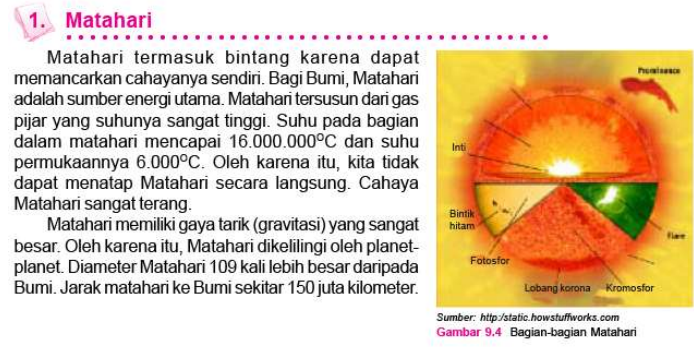

\section{Gambar 11. Marker matahari}

d. Marker Asteroid

Marker ini merupakan marker Asteroid, jika kamera pada aplikasi Tata Surya AR ini maka aplikasi akan menampilkan objek 3D Asteroid dan informasi mengenai Asteroid.



Gambar 12. Marker Asteroid

\section{KESIMPULAN}

Setelah melakukan penelitian dan pembahasan, maka kesimpulannya adalah:

a. Dengan adanya aplikasi Tata Surya AR yang berbentuk 3D, maka objek 3 Dimensi yang timbul bisa dijadikan sebuah alat peraga virtual untuk menggantikan alat peraga fisik yang tidak ada. Sementara itu, video bisa menambah wawasan tentang tata surya dengan cara menonton video. Ketidak adaan 
alat peraga dapat digantikan melalui aplikasi augmented reality.

b. Tata Surya AR menarik untuk digunakan dalam pembelajaran objek-objek tata surya dengan menggunakan objek 3D yang muncul dari aplikasi sebagai modelnya yang mempunyai animasi pergerakan rotasi pada setiap objek planet. Objek yang timbul di aplikasi berbentuk 3 Dimensi dan video.

c. Marker yang digunakan adalah buku pelajaran itu sendiri, jadi siswa bisa menggunakan aplikasi sambil belajar. Sehingga dengan ini siswa dapat belajar sambil melihat bentuknya secara 3D.

\section{DAFTAR PUSTAKA}

[1] Admiranto. A. G. 2009. Menjelajahi Tata surya, Yogyakarta: PT. Kanisius.

[2] Andriyadi. A. 2011. Augmented Reality with ARToolKit, Jakarta: Augmented Reality Team.

[3] Creighton, R.H. 2010. Unity 3D Game Development by Example Beginner's Guide, Birmingham: Packt Publishing.

[4] Mario Fernando Rentor. 2013. Rancang Bangun Perangkat Lunak Pengenalan Motif Batik Berbasis Augmented Reality. Yogyakarta, Program Studi Magister Teknik Informatika, Program Pasca Sarjana, Universitas Atma Jaya Yogyakarta. Tesis.

[5] Patkar, R.S, Singh, S.P, and Birje, S.V. 2013. Marker Based Augmented Reality Using Android $O S$, Mumbai: International Journal of Advanced Research in Computer Science and Software Engineering.

[6] Priyatin, S. 2015. Minat baca Anak Infonesia hanya 0,01 Persen http://regional.kompas.com/read/2015/05/25/17 565591/Yayuk.Basuki.Minat.Baca.Anak.Indone sia.Hanya.0.01.Persen, diakses pada 1 Agustus 2016, 21:10 WIB

[7] Putra, A.W. 2015. Vuforia - SDK Canggih untuk mewujudkan Aplikasi dan Game dengan Teknologi Augmented Reality, https://teknologijurnal-.com/vuforia/, diakses pada 18 Augustus 2016, 20:16 WIB

[8] Rachman, A.F. 2015. Android kuasai Asia Tenggara, Indonesia Paling Juara.http://inet.detik.com/read/2015/10/27/103 538/3054169/317/android-kuasai-asia-tenggaradi-indonesia-paling-juara, 8 Juni 2016, 19:46 WIB

[9] Saputra, Agus. 2014. Forum Diskusi dengan PHP dan MYSQL. CV. ASFA Solution. Cirebon.

[10] Wagner, D. \& Schmalstieg, D. 2012. History and Future of Tracking for Mobile Phone Augmented Reality. Graz University of Technology, I. 